\title{
High-Temperature Coatings for Environmental Protection
}

\author{
VILUPANUR A. RAVI ${ }^{1,2}$ \\ 1.-Department of Chemical \& Materials Engineering, California State Polytechnic University, \\ Pomona, 3801 W. Temple Avenue, Pomona, CA 91768, USA. 2.-e-mail: vravi@csupomona.edu
}

Increasing the lifetime of metallic alloy components in high-temperature $\left(>550^{\circ} \mathrm{C}\right)$ corrosive environments by the application of protective coatings is an important area of study that affects a broad spectrum of industry. In this issue, three articles address different aspects of the theme "High-Temperature Coatings for Environmental Protection."

The first article in this compilation deals with protective coatings on austenitic stainless steels. This paper, by Lopez et al., reports on an investigation relating the austenite stability of several grades of commercial stainless steels to the thickness of aluminide coatings formed on their surfaces using the halide-activated pack cementation process. The authors computed the austenite stability by determining the ratio of nickel to chromium equivalents for each of the alloys. The coating morphologies varied for the different steels coated under the same processing conditions. The thickness of the inner diffusion zone (present in all of the coatings studied) was inversely correlated to the austenite stability of the steels. The paper also reports on the correlation between the microhardness and aluminum composition profiles obtained from measurements on the coated cross-sections of the steels. The findings are important in designing pack coating processes that will coat austenitic stainless steels without transforming the substrate to ferrite.

In the second paper in this collection, Dryepondt et al. discuss the oxidation, creep and fatigue properties of uncoated and coated alloy $31 \mathrm{~V}$, a nickelbased alloy used in the exhaust valves of natural gas reciprocating engines. In this study, the authors examine the possibility of using aluminide coatings for increasing valve lifetimes. Towards this end, they conducted cyclic oxidation tests at $800^{\circ} \mathrm{C}$ and creep and fatigue tests at $816^{\circ} \mathrm{C}$. Coatings were

Vilupanur A. Ravi is the guest editor for the Corrosion \& Environmental Effects Committee of the TMS Structural Materials Division, and coordinator of the topic High-Temperature Coatings for Environmental Protection in this issue. applied by slurry and pack cementation methods. The pack aluminide coatings provided the alloys with the most resistance to oxidative attack followed by the slurry-coated coupons while the uncoated alloy exhibited mass loss. The authors report that the creep rupture life for these alloys (coated and uncoated) were similar after the prescribed heat treatment schedule for this alloy. According to this study, the high cycle fatigue lifetimes of the slurry coated alloys showed more variability in comparison with the pack coated and uncoated alloy specimens with the latter two showing similar behavior. They conclude by noting that while aluminide coatings have potential value in this application, care must be taken to select coating process parameters consistent with heat treatment schedules.

In the third and final paper in this sequence, Montero et al. discuss environmentally friendly slurry coatings. The authors describe recent advances they have made in the development of slurry compositions that can be applied to the surface of nickel- and iron-based alloys. The slurries described consist essentially of metal powders, polyvinyl alcohol and water. High- and low-aluminum activity slurries as well as platinum-, cobalt-, chromium- and titanium-modified slurries were applied to the surface of a nickel-based superalloy. For the iron-based alloy surface, the slurries described include high and low activity aluminum, and siliconand nickel-modified ones. Microstructures of the coated cross-sections are presented and discussed. According to this study, the activity of aluminum in the slurries can be controlled and the co-deposition of selected elements is more readily achieved. The authors assert that these slurries are non-toxic, environmentally friendly and can be customized.

In summary, this selection of papers highlights different aspects of high-temperature coatings developments and offers a snapshot of the current activities in this critical area of research.

The following papers being published under the topic of High-Temperature Coatings for Environmental Protection provide excellent details and 
research on the subject. To download any of the papers, follow the url http://link.springer.com/jour nal/11837/67/1/page/ 1 to the table of contents page for the January 2015 issue (vol. 67, no. 1).

- "Effect of Austenite Stability on Pack Alumnizing of Austenitic Stainless Steel" Christopher Lopez, Armen Kvryan, Shahan Kasnakjian, Armando Coronado, Sutine Sujittosakul, Obed Villalpando, and Vilupanur A. Ravi.
- "Oxidation, Creep And Fatigue Properties of Bare and Coated $31 \mathrm{~V}$ Alloy" Sebastien Dryepondt, Samuel J. Jones, Ying Zhang, Phillip J. Maziasz, and Bruce A. Pint.

- "A Novel Type of Environmentally Friendly Slurry Coating" Xabier Montero, Mathias C. Galetz, and Michael Schütze. 